\title{
A survey of prosthetic eye wearers to investigate mucoid discharge
}

This article was published in the following Dove Press journal:

Clinical Ophthalmology

9 May 2012

Number of times this article has been viewed

\section{Keith Pine ${ }^{\prime}$ \\ Brian Sloan ${ }^{2}$ \\ Joanna Stewart ${ }^{3}$ \\ Robert J Jacobs' \\ 'Department of Optometry and Vision Science, ${ }^{2}$ Department of Ophthalmology, New Zealand National Eye Centre, ${ }^{3}$ Section of Epidemiology and Biostatistics, School of Population Health, University of Auckland, Auckland, New Zealand}

Correspondence: Robert J Jacobs Department of Optometry and Vision Science, New Zealand National Eye Centre, University of Auckland, Private Bag 92019, Auckland, II42, New Zealand

Tel +6493737599 ext 85019

Email r.jacobs@auckland.ac.nz
Background: This study aimed to better understand the causes and treatments of mucoid discharge associated with prosthetic eye wear by reviewing the literature and surveying anophthalmic patients.

Methods: An anonymous questionnaire was completed by 429 prosthetic eye wearers who used visual analog scales to self-measure their discharge experience for four discharge characteristics: frequency, color, volume, and viscosity. These characteristics were analyzed with age, ethnicity, years wearing a prosthesis, eye loss cause, removal and cleaning regimes, handwashing behavior, age of current prosthesis, and professional repolishing regimes as explanatory variables. Eighteen ocularists' Web sites containing comments on the cause and treatment of discharge were surveyed.

Results: Associations were found between discharge frequency and cleaning regimes with more frequent cleaning accompanying more frequent discharge. Color was associated with years of wearing and age, with more years of wearing and older people having less colored discharge. Volume was associated with cleaning regimes with more frequent cleaners having more volume. Viscosity was associated with cleaning regimes and years of wearing with more frequent cleaning and shorter wearing time accompanying more viscous discharge. No associations were found between discharge characteristics and ethnicity, eye loss cause, hand washing, age of current prosthesis, or repolishing regimes. Forty-seven percent of ocularists' Web sites advised that discharge was caused by surface deposits on the prosthesis, $29 \%$ by excessive handling of the prosthesis, and $24 \%$ by other causes.

Conclusions: A standardized treatment protocol for managing discharge is lacking. More frequent prosthesis removal and cleaning was associated with more severe discharge, but the direction of cause and effect has not been established. Professional repolishing regimes had limited impact on discharge experience. Further research into the socket's response to prosthetic eye wear, including the physical, chemical, and biological elements of the conjunctiva, the socket fluids, and the deposits that cover the prosthetic eye is recommended.

Keywords: anophthalmia, prosthetic eye, secretions, discharge, deposits

Mucoid discharge associated with prosthetic eye wear is a common occurrence that impacts on the quality of life of people who have lost an eye. Pine et $\mathrm{al}^{1}$ report that discharge is the second most important concern for experienced prosthetic eye wearers after health of their remaining eye and affects $93 \%$ of wearers $-60 \%$ of these on a daily basis.

The literature does not provide a complete understanding of the nature and causes of discharge associated with prosthetic eye wear. This is reflected in the range of opinions offered by ocularists' Web sites and the lack of a standardized treatment 
protocol for this distressing condition. ${ }^{2}$ This study attempts to provide a better understanding of discharge by examining aspects of prosthetic eye wear that are likely to be associated with discharge. It investigates the influence on discharge of hand washing before handling the prosthesis, removal and cleaning regimes, repolishing frequency, and the effect on discharge of wearers' age and wearers' ethnicity.

\section{Methods}

A survey of 18 ocularist websites ${ }^{3-20}$ found to provide advice about mucoid discharge and/or prosthetic eye cleaning regimes was carried out. Ethics approval to send a questionnaire to prosthetic eye wearers in New Zealand was obtained from the Multi-region Ethics Committee of the Ministry of Health, New Zealand. The New Zealand Artificial Eye Service, the Royal New Zealand Foundation of the Blind, the Accident Compensation Corporation, and five District Health Boards agreed to search their databases and post the anonymous questionnaire to their anophthalmic patients. A total of 1373 letters with the questionnaires were mailed out. No record could be kept of "Gone No Address" returns or if any patients received more than one letter.
The questionnaire was divided into two sections: Section 1 requested demographic information and information about how the prosthetic eye was cared for. Data were gathered on age, ethnicity, date of eye loss, why the eye was lost, date of fitting the present prosthesis and date of last professional repolish, how often the prosthesis was removed for cleaning, the reason for adopting the particular cleaning regime, whether hands were washed before removing the prosthetic eye, whether the prosthesis was left out overnight, how easy could the prosthesis be removed, and whether help was required to remove it. Section 2 asked participants to describe the nature and frequency of any discharge they were currently experiencing using the visual analog scales shown in Figure 1. There was a scale for each of the four discharge characteristics: color, viscosity, volume, and frequency. Each scale was continuous with 0 at the left end and 10 at the right end. The descriptors placed above the scale assisted participants to mark a position along the scale that best described their experience with the particular discharge characteristic. Numbers and descriptors towards the right end of each scale reflected greater severity of discharge experience. For example, on the viscosity scale

\begin{tabular}{|c|c|c|c|c|c|c|c|}
\hline Never & & & Weekly & Twice-weekly & Daily & Twice-daily & Continuous \\
\hline 0 & 1 & 2 & 3 & 4 & 6 & 7 & 10 \\
\hline
\end{tabular}

\section{Color of discharge}

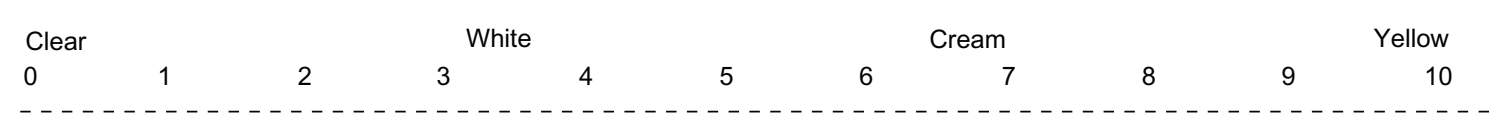

\section{Volume of discharge}

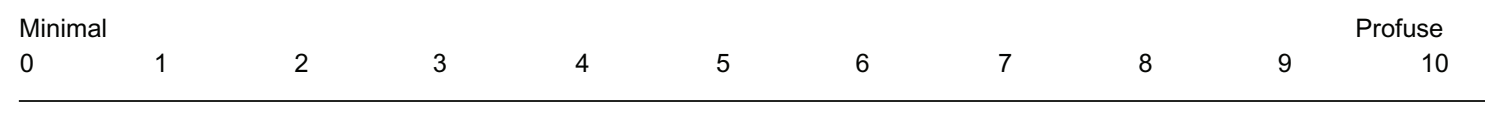

\section{Viscosity (stickiness/thickness) of discharge

\begin{tabular}{llllllllll} 
Runny & & \multicolumn{1}{c}{ Stringy } & \multicolumn{9}{c}{ Moderately thick } & & Very thick \\
0 & 1 & 2 & 3 & 4 & 5 & 6 & 7 & 9 & 10
\end{tabular}

Figure I Visual analog scales for self-measuring four discharge characteristics. 
"runny" corresponded with 0-1, "stringy" at 3-4 suggests the formation of mucus strands, "moderately thick" was placed at 6-7, and "very thick" at 9-10 reflected the most severe experience.

The participants were then asked whether they felt that having their prosthetic eyes professionally repolished improved discharge and if so, how long the improvement lasted.

\section{Statistical analysis}

To investigate factors related to the frequency, volume, color, and viscosity of discharge, a general linear model was used (one for each outcome) with explanatory variables of age, ethnicity (European/other, Maori/Pacific, Asian), years wearing a prosthesis, reason for eye loss (accident, medical, congenital), frequency cleaned (at least once per week [1], less than once a week but at least once a month [2], less than once a month but at least once a year [3], never [4]), frequency of professional repolish (entered as more frequently than yearly [1], every one to two years [2], less than every two years but sometimes [3], never [4]), hand washing before removing (coded as no [0], yes sometimes [1], yes mostly [2], yes always [3]), and age of current prosthesis. As many participants did not record the frequency of professional repolishing, the analyses were first run including this variable but it was removed when not shown to be associated with any discharge characteristic.

\section{Results}

Forty-seven percent of ocularists' websites advised that mucoid discharge was caused by surface deposits that build up on the prosthetic eye, $29 \%$ that it was caused by excessive handling of the prosthesis, and $24 \%$ gave other causes, such as dust and dirt in the socket.

The recommended cleaning regime for $47 \%$ of the sites was to not remove the prosthesis unless it was uncomfortable or discharging. Thirty-five percent recommended that the prosthetic eye should be left alone and only removed by the ocularist yearly or every 6 months. A further $18 \%$ recommended a set routine for removal and cleaning that varied between daily and twice monthly (Table 1).

Of the 1373 questionnaires mailed to New Zealand prosthetic eye wearers, 429 (31\%) were completed and returned.

\section{Prosthetic eye removal and cleaning regimes}

Of the wearers who completed this section of the questionnaire, $35 \%$ removed and cleaned their prosthetic
Table I Summary of advice relating to discharge published on ocularists' websites

Percentage

\begin{tabular}{ll}
\hline Cause of discharge $(\mathbf{n}=\mathbf{~ I 7})$ & \\
Build-up of deposits & $47 \%$ \\
Handling the prosthesis & $29 \%$ \\
Other & $24 \%$ \\
Recommended cleaning regime $(\mathbf{n}=\mathbf{I 7})$ & \\
Do not remove unless uncomfortable or discharging & $47 \%$ \\
Leave in and do not handle & $35 \%$ \\
Set regime - daily to twice monthly & $18 \%$ \\
\hline
\end{tabular}

eyes daily, $15 \%$ less frequently than daily but up to and including weekly, $8 \%$ between weekly and monthly, 14\% monthly, and $27 \%$ less frequently than monthly.

Participants' reasons for their particular cleaning regime included excessive discharge, discomfort, hygiene, because they were advised to, and habit. The most common reasons cited were excessive discharge or discomfort and hygiene, although hygiene was less important for those removing their prostheses less frequently than monthly.

\section{Variables associated with discharge measures}

Frequency of repolish was not shown to be associated with any of the measures of discharge so was not included in the analyses reported due to the number of responders not answering this question (Figure 2, Table 2).

\section{Frequency of discharge}

There was strong evidence of an association of frequency of cleaning with frequency of discharge $(P<0.0001)$ with those cleaning less often reporting a lower frequency of discharge. No other variables could be shown to be associated with frequency of discharge.

\section{Color of discharge}

There was strong evidence of an association between period of prosthetic eye wear and color of discharge $(P=0.006)$ with those who had had their prosthetic eye longer reporting a less colored discharge. There was also evidence of an association of age with discharge color with older people reporting a less colored discharge. No other variables could be shown to be associated with the color of discharge.

\section{Volume of discharge}

There was strong evidence of an association of frequency of cleaning with volume of discharge $(P=0.002)$ with those cleaning less often reporting a lower volume of discharge. 


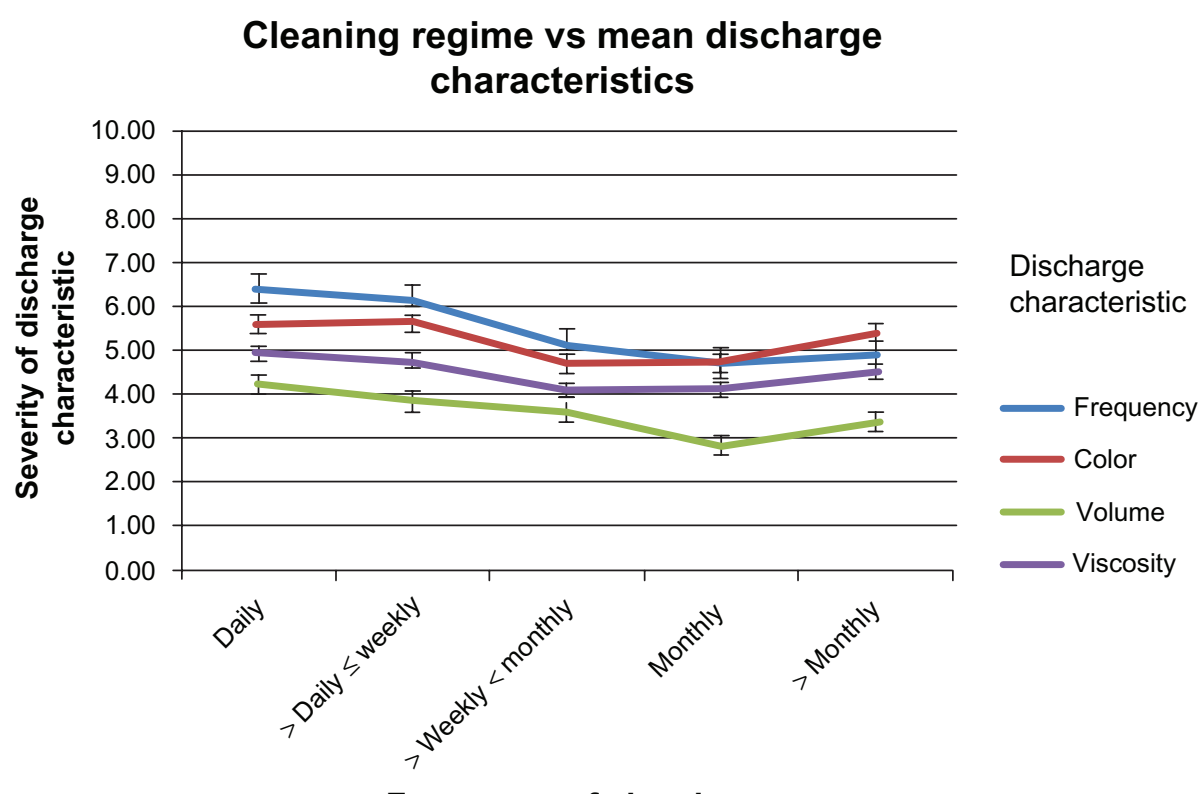

Frequency of cleaning

Figure 2 Frequency, color, volume, and viscosity of discharge as a function of different removal and cleaning regimes.

Note: Bars indicate standard error.

No other variables could be shown to be associated with volume of discharge.

\section{Viscosity of discharge}

There was evidence of an association of frequency of cleaning with viscosity of discharge $(P=0.02)$ with those cleaning less often having a lower viscosity of discharge score. There was also evidence of longer periods of prosthetic eye wear being associated with viscosity with longer time having a lower viscosity score. No other variables could be shown to be associated with viscosity of discharge.

\section{Professional repolishing regimes}

Fifty-one percent of the participants had their prosthetic eyes repolished every year, $9 \%$ more often than yearly, and $40 \%$ less often. When asked directly "Does having your prosthetic eye(s) professionally repolished improve discharge? (Yes or No)," $44 \%$ of wearers reported no improvement. When asked directly, "If yes, how long does the improvement last," $18 \%$ said that the improvement lasted less than 1 month, $20 \%$ that the improvement lasted between 1 and 6 months, and 5\% that the improvement lasted longer than 6 months. Fourteen percent were unsure (Figure 3).

\section{Discussion}

The survey of ocularists' Web sites revealed that the cause of discharge has not been settled. The largest group believed that the main cause was the buildup of surface deposits on prosthetic eyes, but the sites appear to contradict this with a majority $(82 \%)$ recommending that prosthetic eyes (with deposits) (a) never be removed and cleaned or (b) only be removed and cleaned if causing discomfort or discharge. Osborn and Hettler surveyed members of the American Society of Ocularists in 2007 and found that $31 \%$ recommended to patients that they remove and clean their prosthesis "whenever the socket felt irritated," $25 \%$ recommended monthly removal, and $22 \%$ recommended that their prosthesis be removed "whenever it is dirty." They noted that further studies need to be conducted so a consensus can be achieved by ocularists and a standardized set of treatment protocols developed. ${ }^{2}$

The website of the UK National Health Service (NHS) National Prosthetic Eye Service ${ }^{20}$ advises patients to remove and clean their prosthetic eyes at least once every 30 days, but daily cleaning or several times daily cleaning is also recommended if there is a lot of discharge. Their recommended cleaning method is to rub the prosthesis gently with the fingers using warm water and mild nonscented soap. The NHS website suggests that cleaning the prosthetic eye removes the main cause of discharge, which is a buildup of dirt and dust from the environment. This advice may be compared with the opinion of LeGrand ${ }^{21}$ that a "properly designed, perfectly polished prosthesis is all that is required for total comfort with no excess secretions. Such a prosthesis need 


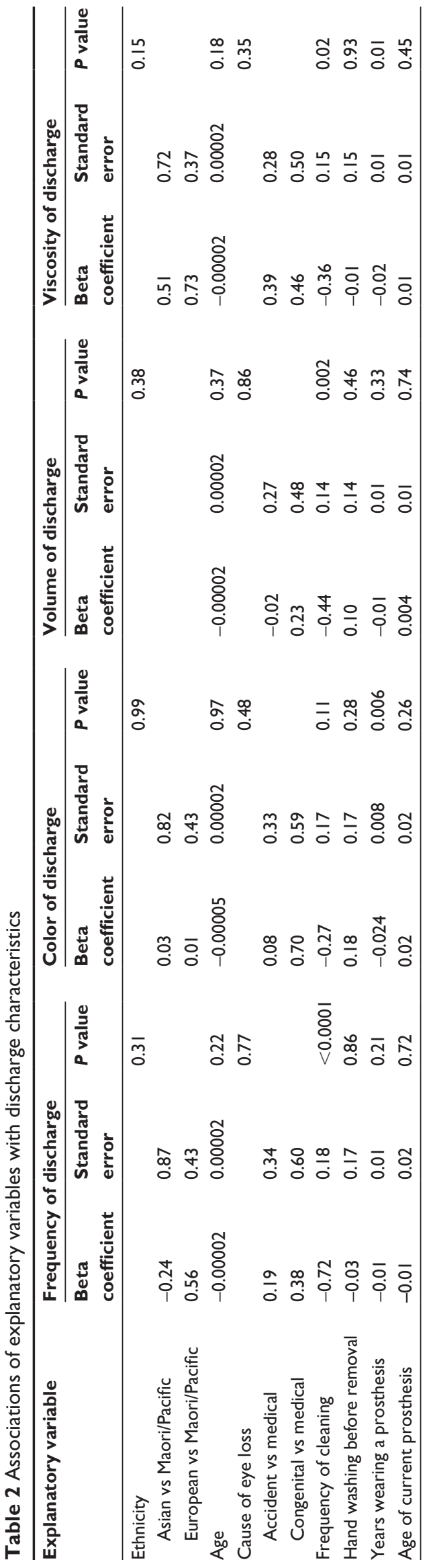

only be removed once each year for professional cleaning to remove natural deposits and restore its polished surface." These two differing recommendations appear to be based on different assumptions. The UK recommendation suggests that cleaning is most important in managing discharge. LeGrand states that the most important factors in managing discharge are proper design (undefined in his paper) and finish of the surface of the prosthesis.

The literature has paid limited attention to the problem of discharge. Vasquez and Linberg ${ }^{22}$ and Kim et $\mathrm{a}^{23}$ found that there were bacteriologic and cytologic differences between anophthalmic and natural sockets but that these differences were not found to be associated with symptoms of discharge. In 1983, Jones and Collin ${ }^{24}$ classified the causes of discharging sockets. They associated acute discharge with viral or bacterial conjunctivitis. Chronic discharge with recurrent symptoms often did not respond to topical antibiotics so causes other than infection were implicated. Their classification achieved its aim of allowing more accurate diagnosis of infections but left open the question of effective treatment for ongoing discharge problems.

Allen et $\mathrm{al}^{25}$ found that patients with noteworthy problems had only half as much basic tear secretion in their anophthalmic sockets as those without problems. They suggested that aqueous or oily prosthetic lubricants might be of value. Fett et $\mathrm{al}^{26}$ evaluated the need for additional lubrication in 200 anophthalmic patients and found that $23 \%$ required supplementation. However, neither Allen nor Fett directly linked low basic tear production or the use of prosthetic lubrication with the discharge problem. Deposit formation on contact lens materials has been investigated, ${ }^{27,28}$ but that work has not yet been extended to prosthetic eyes.

Table 3 presents a summary of the putative causes of discharge noted in the above literature together with patients' comments about discharge taken from a survey of 63 anophthalmic patients in $2009 .{ }^{1}$ A limitation of this study was that many of the causes noted in Table 3 (for example, socket and eyelid problems or unsuitable prostheses) were not investigated. Discharge was likely to be more severe in the presence of these problems.

Vasquez and Linberg ${ }^{22}$ did not investigate hand-washing behavior, but hand washing may have been a factor in their additional finding that patients who frequently manipulated their prosthesis had a significantly higher proportion of Gramnegative bacteria in the conjunctiva of their sockets. Whether wearers hand washed or not and in line with Vasquez and Linberg, this study found no evidence of an association of hand washing with discharge experience. 


\section{Lasting effect of re-polishing artificial eyes}

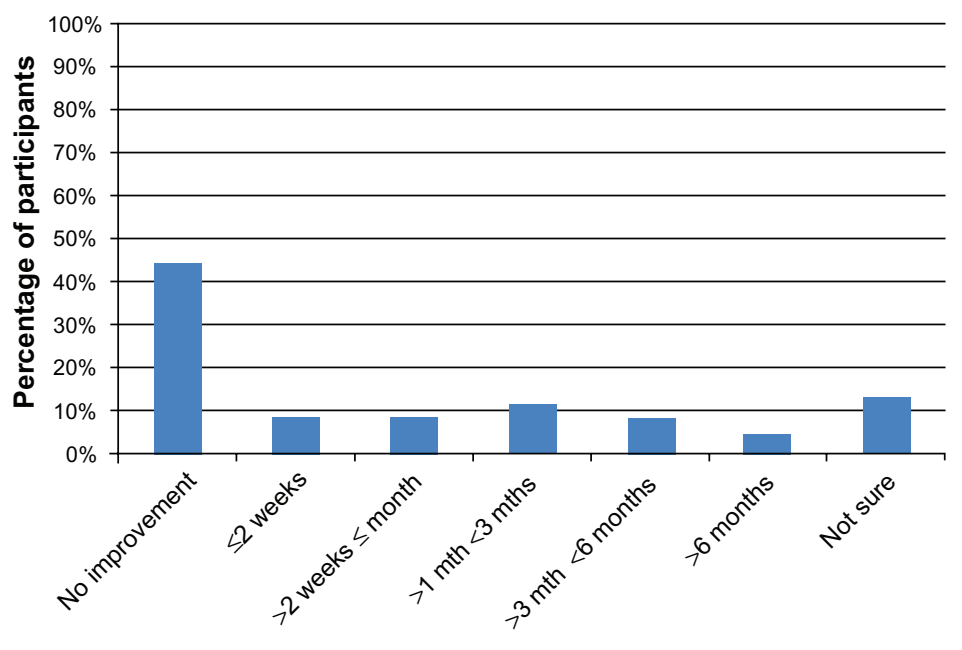

Lasting effect of polish improvement

Figure 3 The duration of the effect on discharge experience of professional repolishing.

The finding that more frequent removal and cleaning was associated with more discharge does not indicate the direction of the effect as wearers who experience discharge are likely to clean their prosthesis more frequently than those who have no discharge. This is borne out with frequent cleaners

Table 3 Putative causes of mucoid discharge summarized from ocularists' websites, formal literature, and subjective comments from patients in a previous study

\begin{tabular}{ll}
\hline Specific causes & \\
Viral or bacterial infections & Common cold, etc \\
Environmental allergens & Pollens, dust mites, etc \\
Irritants in the socket & Dust, stray eye lashes, smoke-filled \\
& rooms, etc \\
Eye stress & Night driving, reading, computers, etc \\
Drying conditions & Wind, air conditioners, etc \\
Clinical intervention & Impression taking, etc \\
Damaging behavior & Excessive rubbing of prosthesis, etc \\
Nonspecific causes & \\
Physical irritation & Size, surface finish, surface deposits, weight, \\
from prosthesis & material and manufacturing process, etc \\
Deposits on prosthesis & Protein, dirt, etc \\
Shape and fit of prosthesis & Pooling of secretions in the socket \\
Removal regime & Daily, monthly, never \\
Cleaning agents & Soap, detergents \\
Socket hygiene & Contamination from fingers and eyelids \\
Lacrimal system & Defective tear production and drainage \\
Anatomical limitations & Poor lid closure, grafted tissue, scarring, etc \\
Medical conditions & Unwell, side effects from drugs \\
Orbital implant & Extrusion, conjunctival inclusion cysts, \\
granuloma \\
Infective focus (blepharitis, meibomianitis)
\end{tabular}

citing discharge as the reason they cleaned more often than infrequent cleaners. Clearly, having an uncomfortable and/ or discharging socket is motivation to remove and clean the prosthetic eye frequently. However, this behavior could mask the problem for a number of wearers if frequent cleaning was contributing to the discharge in the first place. Evidence about the cause of discharge may be found by investigating the physical interface between the prosthesis and the conjunctiva. Present at this interface are the physical, chemical, and biological elements of the conjunctiva, the socket fluids, and the deposits that cover the prosthetic eye.

The association between longer periods of prosthetic eye wear and less colored and viscous discharge may indicate that the socket accommodates prosthetic eyes better over time. However period of wear was not shown to affect frequency and volume of discharge, which are more important characteristics for wearing comfort. The finding that older people are likely to have discharge with less color may be of value to future researchers investigating discharge.

Annual repolishing of prosthetic eyes is recommended by a large majority of ocularists, and $60 \%$ of wearers undertook repolishing at least this often. It was surprising to find that wearers in this study thought that professional repolishing did not have any significant effect on their discharge experience because it is commonly assumed that a clean smooth surface on the prosthetic eye is paramount. When asked directly whether repolishing improved discharge, $62 \%$ of wearers reported no improvement or that any improvement lasted less than 1 month. This result suggests that professional repolishing may play only a minor part in reducing 
discharge and that personal removal and cleaning regimes are more important.

There appears to be no consensus among practitioners for treatment of mucoid discharge associated with prosthetic eye wear, and there remains a large and underinvestigated group of patients with nonspecific discharge for which many causes of discharge have been postulated. Further research is warranted because prosthetic eye wearers ranked discharge as the second most important concern after health of their remaining eye. ${ }^{1}$ We have taken initial steps to investigate the discharge issue with this retrospective study and have found as expected that more severe discharge was associated with frequent removal and cleaning. Personal removal and cleaning regimes appear to be more important than professional repolishing, which appeared to have limited impact on discharge experience. Further research into the socket's response to prosthetic eye wear, including the physical, chemical, and biological elements of the conjunctiva, the socket fluids, and the deposits that cover the prosthetic eye is recommended.

\section{Disclosure}

The authors report no conflicts of interest in this work.

\section{References}

1. Pine K, Sloan B, Stewart J, Jacobs RJ. Concerns of anophthalmic patients wearing prosthetic eyes. Clin Experiment Ophthalmol. 2011; 39(1):47-52.

2. Osborn KL, Hettler D. A survey of recommendations on the care of ocular prostheses. Optometry. 2010;81(3):142-145.

3. Archibald Maxillofacial Prosthetics Inc. Custom artificial eyes. Available from: http://artificialeyecare.com. Accessed April 29, 2012.

4. Prosthetic Eye Clinic. Available from: http://www.artificialeyeclinic.com/ index.html. Accessed April 29, 2012.

5. Carvelho B. Eyes Alive. Available from: http://www.eyesalive.co.za. Accessed April 29, 2012.

6. Carolina Eye Prosthetics Inc. Available from: http://www.carolinaeyepro stheticsinc.com. Accessed April 29, 2012.
7. Centre for Custom Prosthetics. Available from: http://www. artificialeyesplastic.com. Accessed April 29, 2012.

8. Cos-Medic Prosthetic Eyes. Available from: http://www.artificialeyes com.au. Accessed April 29, 2012.

9. D Danz and Sons. Available from: http://www.ddanzandsons.com. Accessed April 29, 2012.

10. Erickson's. Available from: http://www.ericksoneyes.com. Accessed April 29, 2012.

11. Sanders SE. Fairbanks Ocular Prosthetics. Available from: http://www. fairbanksocular.com. Accessed April 29, 2012.

12. Prosthetic Eyes by Paul and Jenny Geelen. Available from: http://www. geelen.com.au. Accessed April 29, 2012.

13. Kolberg Ocular Prosthetics. Available from: http://www.artificialeye.net. Accessed April 29, 2012.

14. Marie Allen Ocularist. Available from: http://www.artificial-eyeclinic.com. Accessed April 29, 2012.

15. Haddad SE. Ocular Prosthetics Inc. Available from: http://www. ocularpro.com. Accessed April 29, 2012.

16. Robin Brammar Ocularist. Available from: http://www.robinbrammar. co.uk. Accessed April 29, 2012.

17. siniora.gr Experts in Ocular Prosthetics. Available from: http://www. siniora.gr/index.htm. Accessed April 29, 2012.

18. South Eastern Ocularists. Available from: http://www.seocularists.com. Accessed April 29, 2012.

19. Strauss Eye Prosthetics Inc. Available from: http://www.strausseye.com/ Services.aspx. Accessed April 29, 2012.

20. The National Prosthetic Eye Service. Available from: http://www.bfwh. nhs.uk/aes/prosthetic_eye_care.htm. Accessed April 29, 2012.

21. LeGrand JA. Chronic exudate: an unnecessary evil. J Ophthalmic Prosthetics. 1999;4(1):33-40.

22. Vasquez RJ, Linberg JV. The anophthalmic socket and the prosthetic eye A clinical and bacteriologic study. Ophthal Plast Reconstr Surg. 1989;5(4):277-280.

23. Kim JH, Lee MJ, Choung HK, et al. Conjunctival cytologic features in anophthalmic patients wearing an ocular prosthesis. Ophthal Plast Reconstr Surg. 2008;24(4):290-295.

24. Jones CA, Collin JR. A classification and review the causes of discharging sockets. Trans Ophthalmol Socs UK. 1983;103(3):351-353.

25. Allen L, Kolder HE, Bulgarelli EM, Bulgarelli DM. Prosthetic eyes and tear measurements. Ophthalmology. 1980;87(2):155-157.

26. Fett DR, Scott R, Putterman AM. Evaluation of lubricants for the prosthetic eye wearer. Ophthal Plast Reconstr Surg. 1986;2(1):29-31.

27. Ho CH, Hlady V. Fluorescence assay for measuring lipid deposits on contact lens surfaces. Biomaterials. 1995;16(6):479-482.

28. Teichroeb JH, Forrest JA, Ngai V, Martin JW, Jones L, Medley J. Imaging protein deposits on contact lens materials. Optom Vis Sci. 2008;85(12):1151-1164.
Clinical Ophthalmology

\section{Publish your work in this journal}

Clinical Ophthalmology is an international, peer-reviewed journal covering all subspecialties within ophthalmology. Key topics include: Optometry; Visual science; Pharmacology and drug therapy in eye diseases; Basic Sciences; Primary and Secondary eye care; Patient Safety and Quality of Care Improvements. This journal is indexed on

\section{Dovepress}

PubMed Central and CAS, and is the official journal of The Society of Clinical Ophthalmology (SCO). The manuscript management system is completely online and includes a very quick and fair peer-review system, which is all easy to use. Visit http://www.dovepress.com/ testimonials.php to read real quotes from published authors. 